\title{
Dependence of non thermal plasma temperature on the plasma needle conditions
}

\author{
Hamid H.murbat ,Nisreen k. Abdulameer, ZinaA. Kadum,Bayan G. Ali \\ *Physics Department, College of Science for Women, University of Baghdad, Iraq.
}

\begin{abstract}
An atmospheric pressure helium plasma needle type is studied. The plasma isgenerated at (10-40) $k H z a t$ very low power levels. It is in contact with a single electrode and is part of a resonantelectric circuit. The plasma needle consists of glass tube and stainless steel tube concentrated inside it, they are used for guiding the gas flow. The stainless steel tube also serves as the electrode, which is connected to a high-voltage (HV) sub microsecond pulsed direct-current (dc) power supply (amplitudes of up to $40 \mathrm{kV}$ ). The stainless steel tube is made with different outer diameters $(2.7,3.5,5,6) \mathrm{mm}$ and the glass tube was made with different inner diameters $(1,4.4,5.3,10.6) \mathrm{mm}$, the non thermal plasma temperature was measured as a function of high voltage frequency (up to $30 \mathrm{kHz}$ ), and distance from the needle nozzle, for different flow rate of the gas $(1,2,3,4,5) l /$ minfor every stainless steel tube, The helium gas temperature was measured with a digital thermocouple having the "hot" junction covered with a plastic-cap. It is found that the plasma temperature increases with increasing frequency up to given frequency (nearly $15 \mathrm{kHz}$ )and then slow down with increasing frequency, also it is found the maximum temperature measured at the nozzle of the needle $(d=0)$ and the slow down slowly with distance. It is found the diameter of the cylindrical electrode did not had significant effect on the temperature of the plasma.
\end{abstract}

Key words:plasma needle, non thermal plasma, plasma temperature,

\section{Introduction}

The scientific community who studies the plasma state has recently paid much attention to the development of atmospheric pressure plasma sources having the gas temperatures close to the room temperature and to use these plasmas for technologies applied up to now only under low-pressure conditions. The interest in this topic is dictated by a potential economic benefit from numerous non-thermal plasma technologies: plasma assisted chemical vapor deposition, etching, polymerization, protective coating deposition, toxic and harmful gas decomposition, sterilization and decontamination, electromagnetic wave shielding, polymer surface modifications, and so on. These new technologies can be now applied on the materials which can not be treated at low-pressure or can not support the temperature much higher than the room temperature. Such plasmas are placed in non-thermal plasmas category which were defined as having the gas temperature lower than combustion temperature $\left(\mathrm{T}_{\text {gas }}<\mathrm{T}_{\text {combustion }}=2300 \mathrm{~K}\right)$ [1]. A relatively recent review paper presents the generation mechanisms, the appearance of the plasma states and physical.Characteristics of some atmospheric pressure discharges, which can have a non-thermal character and could be cold [2].

Starting from these considerations, different kind of atmospheric pressure non-thermal plasmas were generated, the most important being: plasma needle, plasma pencil, dielectric barrier discharge and plasma jet. Plasma needle was developed by Stoffels and was characterized having in view the electrical and optical characteristics [3], the action on bacterial cells [4] and in vivo treatments of biological tissues [5]. The studies have established that the positive effects of the cold non-thermal plasma treatment is not the effect of the thermal energy radiated by the plasma, but it is the effect of the action of the active species, mainly $\mathrm{O}$ and $\mathrm{OH}$ radicals, and nitric oxide. Puac extended the application area of the plasma needle studying the effect over the biological cells [6]. He also presents a voltampere characteristic of the plasma needle. Inactivation of bacteria and the interaction of the plasma with microbial cells were studied by Laroussi using plasma pencil and dielectric barrier discharge [7, 8]. Plasma pencil was for the firsttime studied by Janca [9], and plasma jet was used by Cheng for modification ofsuperficial characteristics of polymeric fibers [10].

Recently, there were developed other kind of cold plasma sources (some ofthem being biologically compatible) at atmospheric pressure, the mostrepresentative being: hollow slot micro plasmas tested for bacterial deactivation[11]; a surface discharge generated by combining continuous and alternativeelectric fields, plasma which generates hydrogen and is used for deactivation ofairborne microbial-contaminants and for neutralization of indoor $\mathrm{OH}$ radicals, being harmless to the human body [12]; and the so named rf APGD torch, testedfor treatment of cells and biological surfaces [13, 14].

Our study deals with conditions that effects the non thermal plasma needle temperature including frequency, distance from the nozzle of the needle, flow rate and electrode diameter. 


\section{Experiment and methodology}

The experimental arrangement is shown in Fig. 1. It consists of four main Parts: high voltage power supply plasma needle, helium gas, flow-rate control.

The homemade high voltage power supply was made based on flyback transformer, it is able to generate high voltage between $(0-10 \mathrm{kV})$ and frequencies $(0-40 \mathrm{kHz})$.

The plasma needle is made of glass tube and another stainless steel tube concentrated inside the glass tube they are used for guiding the gas flow. The stainless steel tube also serves as high voltage electrode ( the anode), which is connected to a high-voltage (HV), the stainless steel tube is made of different outer diameters $(2.7,3.5,5.1,6) \mathrm{mm}$ and the glass tube is made ofdifferent inner diameters $(1,4.4,5.3,10.6) \mathrm{mm}$ as shown in Figs.1and 2, the stainless steel tube covered with a Teflon tape insulator except $5 \mathrm{~mm}$ was left without Teflon tape insulator. The distance from the tip of the stainless steel tube to the nozzle of the glass tube was about $(1 \mathrm{~cm})$. The helium gas was used as working gas to generate plasma,The helium gas was controlled by flow rate regulator(model MFG.CO.LTD. Tube, England). The gas flow can be adjusted in the range of (0-5) 1/min. The plasma temperature was measured with digital thermocouple (DFP $450 \mathrm{~W}$, Waterproof). To preventthe thermocouple to become an extra-electrode of the discharge, it is covered by Teflon tape.

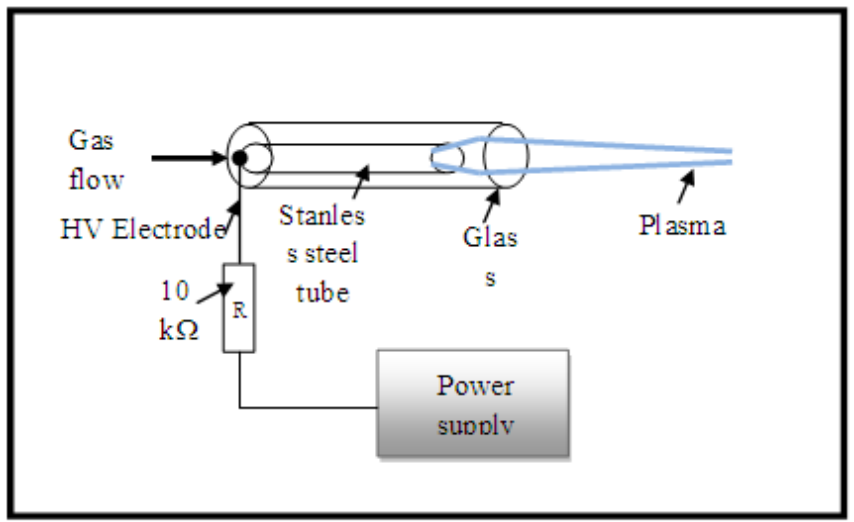

Fig. 1 Schematic of the experimental set up.

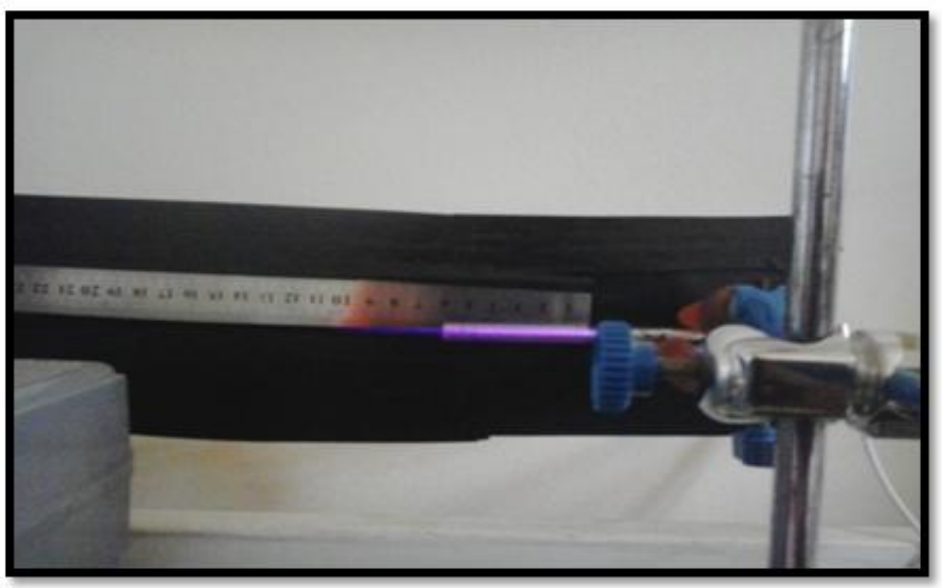

Fig. 2 plasma needle

\section{Results and discussion}

The gas temperature depends both on the helium flow-rate and on the frequency of the electrical field, Fig.(3.a,b,c,d) shows the variation of temperature as a function of the frequency of the high voltage power supply for different flow rate $(1,2,3,4,5) 1 / \mathrm{min}$ and different electrode diameter $\mathrm{D}(2.7,3.5,5.1,6) \mathrm{mm}$. It can be shown that all curves of the temperature have the same behavior. The plasma temperature increases with frequency to reach maximum point at given frequency nearly $(15 \mathrm{kHz})$ and then the temperature of the plasma will be slow dowm again with frequencyIt is found that the temperature increases with frequency up to ( 15 $\mathrm{kHz}$ ) and then slow down slowly this is because the absorption of the energy by the atoms of the gaswas increased with frequency and has maximum value (resonance frequency) at frequency $(15 \mathrm{kHz})$. 
However, it is found that the range of the temperature between (25-32) $\mathrm{C}^{\circ}$ still comparable to the room temperature. Also, it can be show that at given frequency, the temperature decrease with increasing of the flow rate. Concering the diameter of the cylindircal electrode, it found that it is not has segnificant effect on the temperature of the plasma.

Fig . 4 show the variation of the gas temperature as a function of the distance from the nozzle of the plasma needle, for different gas flow-rate $(2,3,4) 1 / \mathrm{min}$ and different diameters of electrode $\mathrm{D}(5,3.5,2.7) \mathrm{mm}$, and fixed frequency $(15 \mathrm{kHz})$.

It is found that the temperature has maximum value at point contact with the nozzle ( $D=0)$ and decrease slow down with the distance from the nozzle, this is because the atoms go out from the nozzle have maximum energy electric breakdown and then lose its energy with distance because of its suffers collisions with air atoms.

\section{Conclusion}

In our present work we design plasma needle with cylindrical stainless steel act as single electrode shielded by glass tube, the study of the effects of the electrode diameter, frequency of the input voltage, flow gas rate and axial distance from the nozzle of the needle on the plasma temperature. It is found that the temperatures of the plasma increases with increasing frequency up to given frequency (nearly $15 \mathrm{kHz}$ ) and then slow down, also the temperature has maximum value at the nozzle of the needle and decrease slow down with the distance from the nozzle. Concering the diameter of the cylindircal electrode, it found that it is not has segnificant effect on the temperature of the plasma.
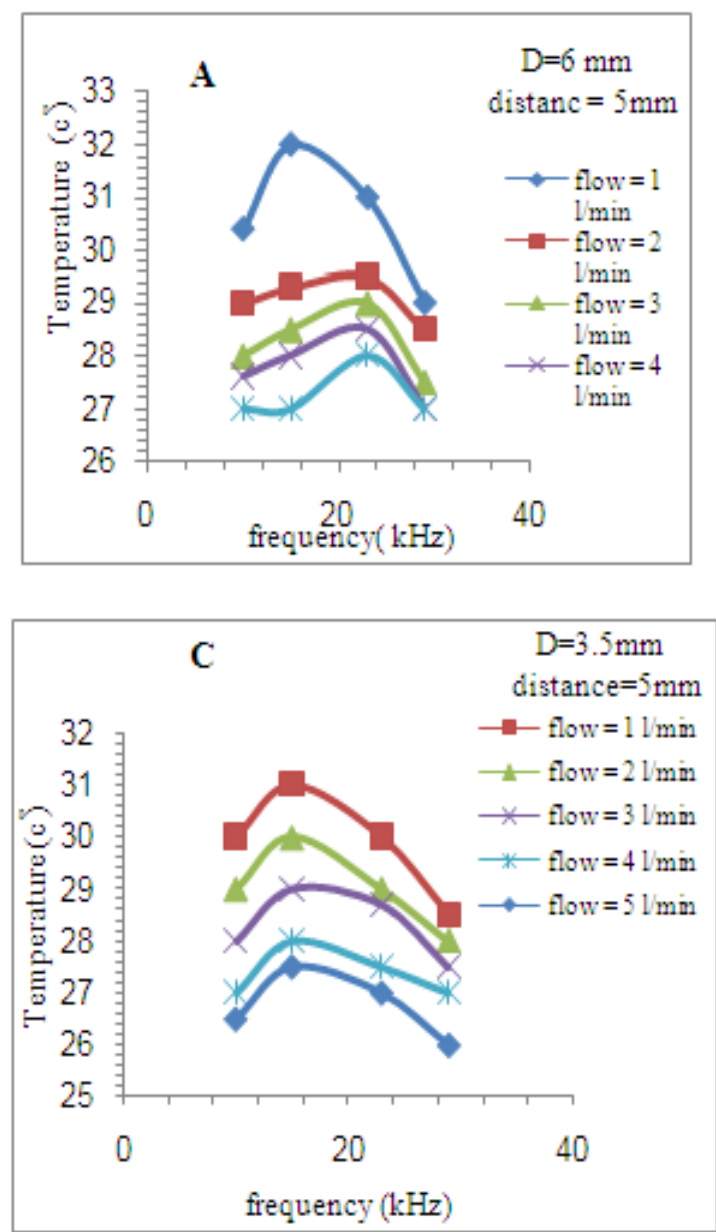
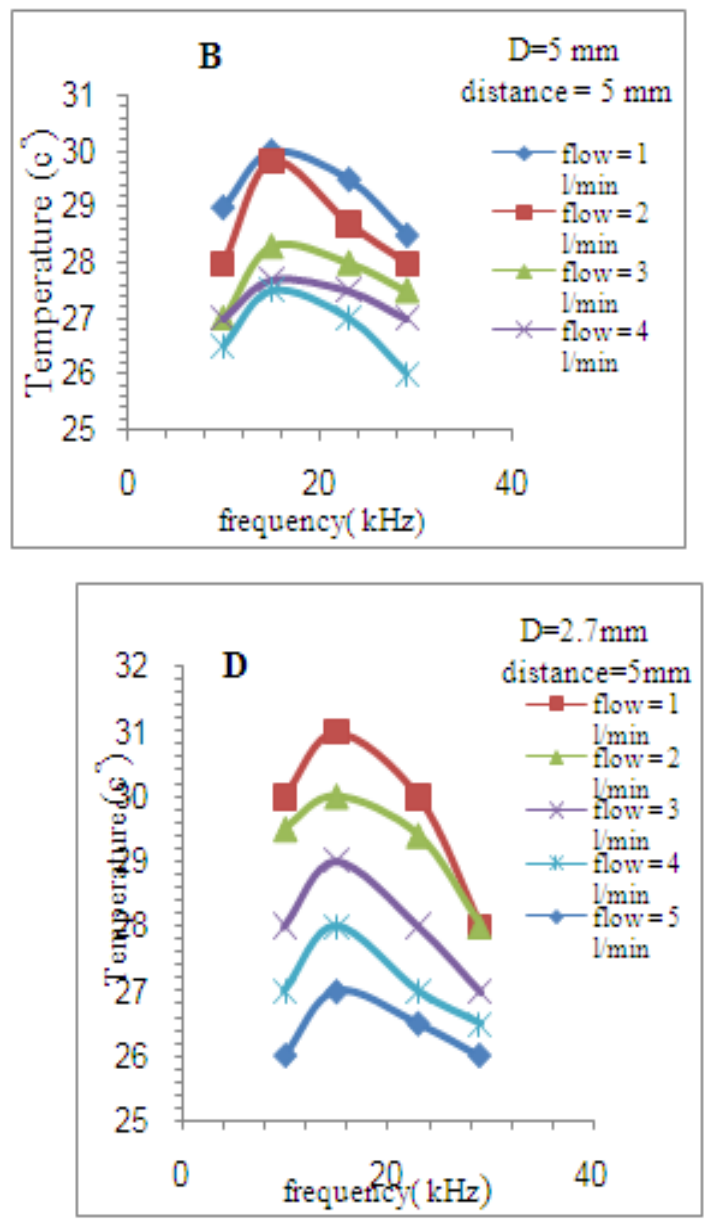

Fig. (3.a,b,c,d) Dependence of the plasma temperature on frequency for various gas flow rate $(1,2,3,4,5) 1 / \mathrm{min}$ and various electrode diameter $(2.7,3.5,5,6) \mathrm{mm}$ 

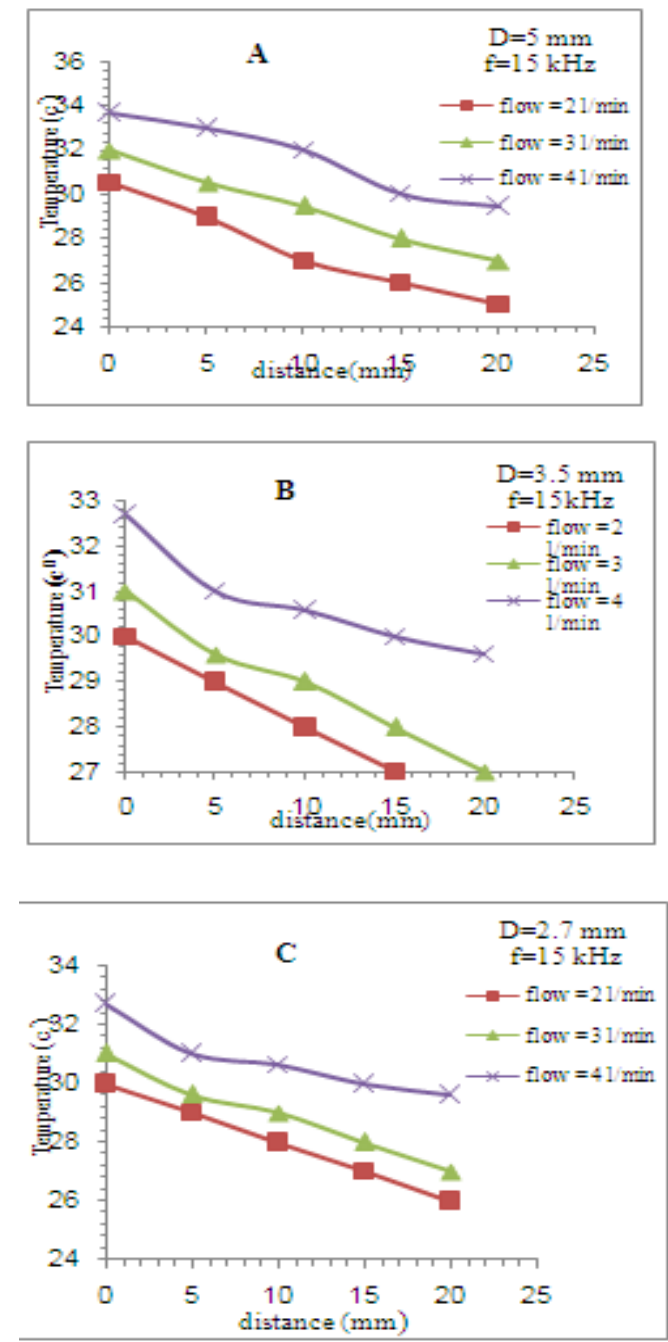

Figure (4.a,b,c) Dependence of the plasma temperature on the distance for various gas flow rate $(1,2,3,4,5) 1 / \mathrm{min}$ and various diameter $(2.7,3.5,5) \mathrm{mm}$, andfrequency $\mathrm{f}=15 \mathrm{kHz}$

\section{References}

[1]. J.S. Chang, Physics and chemistry of plasma pollution control technology, Topical invited, $28^{\text {th }}$ ICPIG, Prague, 2007.

[2]. A. Fridman, A. Chirokov, A. Gutsol, Non-thermal atmospheric pressure discharges, J. Phys. D: Appl. Phys. 38, R1-R24, 2005.

[3]. I. E. Kieft,Van der Laan E. P., E. Stoffels, Electrical and optical characterization of the plasma needle, New Journ. Phys. 6,2004, $149-153$.

[4]. $\quad$ R.E.J. Sladek, E. Stoffels, Deactivation of Escherichia coli by the plasma needle, J. Phys. D: Appl. Phys. 38, 2005, $1716-1721$.

[5]. E. Stoffels, I.E. Kieft, R.E.J. Sladek, L.J.M. van der Bedem, E.P. Van der Laan, M. Steinbuch, Plasma needle for in vivo medical treatment: recent developments and perspectives, Plasma Sources Sci. Technol. 15, S169-S180, 2006.

[6]. N. Puac, Z.L. Petrovic, G. Malovic, A. Dordevic, S. Zivkovic, Z. Giba, D. Grubisic, Measurements of voltage-current characteristics of a plasma needle and its effect on plant cells, J. Phys. D: Appl. Phys. 39, 2006, 3514-3519.

[7]. M. Laroussi, C. Tendero, X. Lu, S. Alla, W.L. Hynes, Inactivation of bacteria by the plasma pencil, Plasma Process. Polym. 3, 2006, 470-473.

[8]. M. Laroussi, D.A. Mendis, M. Rosenberg, Plasma interaction with microbes, New Journ. Phys. 5, 41.1-41.10, 2003.

[9]. J. Yanka, M. Klima, P. Slavicek, L. Zajickova, HF plasma pencil - new source for plasma surface processing, Surf. Coat. Technol. $116-119,547-551,1999$.

[10]. C. Cheng, Z. Liye, R.J. Zhan, Surface modification of polymer fiber by new atmospheric pressure cold plasma jet, Surf. Coat. Technol.200, 2006, 6659-6665,

[11]. A. Rahul, O. Stan, A. Rahman, E. Littlefield, K. Hoshimiya, A.P. Yalin, A. Sharma, A. Pruden, C.A. Moore, Z. Yu, G.J. Collins, Optical and rf electrical characteristics of atmosphericpressure open-air hollow slot microplasmas and application to bacterial inactivation, J. Phys. D: Appl. Phys. 38,2005, 1750-1759,

[12]. H. Nojima, R.E. Park, J.H. Kwon, I. Suh, J. Jeon, E. Ha, H.K. On, H.R. Kim, K. Choi, K.H. Lee, B.L. Seong, H. Jung, S.J. Kang, S. Namba, K. Takiyama, Novel atmospheric pressure plasma device releasing atomic hydrogen: reduction of microbial contaminants and OH radicals in the air, J. Phys. D: Appl. Phys. 40, 2007, 501-509.

[13]. V. Leveille, S. Coulombe, Design an preliminary characterization of a miniature pulsed rf APGD torch with downstream injection of the source of reactive species, Plasma Sources Sci. Technol. 14, 2005, 467-476.

[14]. S. Yonson, S. Coulombe, V. Leveille, R.L. Leask, Cell treatment and surface fictionalization using a miniature atmospheric pressure glow discharge plasma torch, J. Phys. D: Appl. Phys. 39, 2006, . 3508-3513. 